NBER WORKING PAPER SERIES

\title{
PRODUCTIVITY SPILLOVERS, TERMS OF TRADE AND THE "HOME MARKET EFFECT"
}

\author{
Giancarlo Corsetti \\ Philippe Martin \\ Paolo Pesenti
}

Working Paper 11165

http://www.nber.org/papers/w11165

\author{
NATIONAL BUREAU OF ECONOMIC RESEARCH \\ 1050 Massachusetts Avenue \\ Cambridge, MA 02138 \\ March 2005
}

We thank Péter Benkzúr, Caroline Betts, Fabio Ghironi, Marc Melitz, Assaf Razin, Jaume Ventura, and seminar participants at CEPR, Pompeu Fabra University, Tel-Aviv University, Trinity College in Dublin, AEA and SED Meetings for useful comments. Corsetti's work is part of a Research Network on "The Analysis of International Capital Markets: Understanding Europe's Role in the Global Economy”, funded by the European Commission under the Research Training Network Programme (Contract No. HPRN-CT1999-00067). Martin's work is part of a CEPR Research Network on "Specialization Versus Diversification: The Microeconomics of Regional Development and the Spatial Propagation of Macroeconomic Shocks in Europe", funded by the European Commission under the Research Training Network Programme (Contract No: HPRN-CT-2000-00072). The views expressed here are those of the authors, and do not necessarily reflect the position of the Federal Reserve Bank of New York, the Federal Reserve System, or any other institution with which the authors are affiliated. The views expressed herein are those of the author(s) and do not necessarily reflect the views of the National Bureau of Economic Research.

(C) 2005 by Giancarlo Corsetti, Philippe Martin, and Paolo Pesenti. All rights reserved. Short sections of text, not to exceed two paragraphs, may be quoted without explicit permission provided that full credit, including (C) notice, is given to the source. 
Productivity Spillovers, Terms of Trade and the "Home Market Effect"

Giancarlo Corsetti, Philippe Martin, and Paolo Pesenti

NBER Working Paper No. 11165

March 2005

JEL No. F41, F32

\begin{abstract}
This paper analyzes the welfare implications of international spillovers related to productivity gains, changes in market size, or government spending. We introduce trade costs and endogenous varieties in a two-country general-equilibrium model with monopolistic competition, drawing a distinction between productivity gains that enhance manufacturing efficiency, and gains that lower the cost of firms' entry and product differentiation. Our model suggests that countries with lower manufacturing costs have higher GDP but supply a smaller number of goods at a lower international price. Countries with lower entry and differentiation costs also have higher GDP, but supply a larger array of goods at improved terms of trade. The sign of the international welfare spillovers depends on terms of trade, but also on consumers' taste for variety. Higher domestic demand has macroeconomic implications that are similar to those of a reduction in firms' entry costs.

Giancarlo Corsetti

Robert Schuman Centre

European University Institute

Via dei Roccettini 9

I 50016 San Domenico di Fiesole

Italy

giancarlo.corsetti@iue.it

Philippe Martin

CERAS ENS, 48

Boulevard Jourdan 75014

Paris, France

martin-p@enpc.fr

Paolo A. Pesenti

Federal Reserve Bank of New York

333 Liberty Street

New York, NY 10045

and NBER

paolo.pesenti@ny.frb.org
\end{abstract}




\section{Introduction}

A common view in trade and growth theory is that the increased supply of products by a fast-growing economy must be absorbed by international markets at falling prices, causing a deterioration of its terms of trade. The effects of productivity gains are then transmitted positively to the country's trading partners worldwide, thanks to movements in international relative prices. ${ }^{1}$

Underlying this view is the assumption that the set of commodities produced in the global economy and the number of product varieties traded internationally are given and time-invariant. When such assumptions are relaxed, as in Krugman (1989), the tenet that rapidly growing countries must experience a deterioration of their terms of trade becomes questionable. The argument is that countries can change the attributes of their products: product diversification can reduce or prevent altogether the fall in their observed relative prices. Moreover, with an endogenous set of products, the international spillovers of productivity gains are not exclusively driven by relative price movements. The country's trade partners are hurt by higher import prices, but also benefit from the availability of more varieties of goods.

The net welfare effects from these two competing forces depend on the relative magnitude of monopoly power of a country on its terms of trade, as well as consumers' preferences for variety. These considerations raise important issues in the definition and use of appropriate welfare-based price indices, as their product baskets should reflect variations in the array and quality of goods available to consumers (a point stressed by Feenstra (1994) and more recently by Broda and Weinstein (2004a,b) among others).

This paper provides a stylized analysis of the welfare implications of international spillovers. We analyze the determinants of the terms of trade and the world pattern of production within the framework of a two-country macroeconomic model with imperfectly competitive product markets. We let the set of varieties produced in each country to be endogenous, and explicitly take into account the welfare implications of variations in the availability of product varieties and changes in consumption baskets. We allow for transaction costs in international trade which induce home bias in consumption, generating deviations from purchasing

\footnotetext{
${ }^{1}$ This pattern of international transmission is clearly consistent with the Harrod-Balassa-Samuelson hypothesis. According to this hypothesis, countries with higher productivity growth in the tradable sector should experience an increase in the relative price of their nontradable goods. Provided that the elasticity of substitution across tradables produced at home and abroad is sufficiently high, these countries will also experience an appreciation of their real exchange rates. Thus high productivity growth in tradables may simultaneously cause appreciation of the real exchange rate, and weakening of the terms of trade. To the extent that faster productivity growth translates into faster output expansion, an important implication of the association of higher growth with deteriorating terms of trade is that international trade contributes to a stable world income distribution, as emphasized by Acemoglu and Ventura (2002).
} 
power parity (PPP) even though all goods are tradable. Our framework thus encompasses the main elements of trade models that study the 'home market effect'. ${ }^{2}$ It also contributes to the recent but fast-growing literature on general-equilibrium open-economy macroeconomic models with endogenous tradability and product innovation, including Bergin and Glick (2003) and Ghironi and Melitz (2004) among others.

We analyze international productivity differentials by drawing a distinction between productivity in manufacturing - the typical definition of productivity in standard macro models of international transmission - and productivity related to the ability of creating new product varieties and new firms. This distinction plays a crucial role in our analysis of the international transmission, as productivity gains have very different implications for the equilibrium allocation depending on whether they reduce the costs of manufacturing goods, or the costs of firms's entry and product differentiation.

When the number of product varieties is endogenous, one may expect that countries with higher production efficiency in manufacturing tend to supply the widest array of goods. We show that this is not necessarily the case. Under realistic assumptions about parameters values, firms' competition in more productive countries drives down prices and profits, thus reducing the incentive for firms to start producing new goods. Hence, the range of goods varieties supplied by domestic firms falls, driving down the overall supply of varieties in the world economy. Although higher efficiency raises the scale of production of domestic firms, domestic households benefit from productivity gains mainly in terms of lower labor efforts. The country experiences a deterioration of its terms of trade and a depreciation of its real exchange rate.

Conversely, when productivity gains reduce the costs of introducing new varieties and operating new firms, the number of product varieties supplied by domestic firms and available to consumers worldwide rises, while the country's terms of trade improve. If the real exchange rate is conventionally measured without accounting for the greater availability of goods varieties, the country also experiences a real appreciation.

Overall, then, establishing whether productivity improvements affect the production process as opposed to the costs of creating varieties and firms is crucial to predicting their effect on trade volumes, terms of trade, and the real exchange rate. Recent empirical evidence

\footnotetext{
${ }^{2}$ When product markets are imperfectly competitive and internationally segmented, local demand conditions have a different impact on the profits of firms located in different countries. Because of trade costs, firms producing in the market with the stronger demand can take advantage of local market conditions better than firms producing elsewhere. Without entry, profits for the firms located in the country with the larger markets would increase relative to firms abroad. When entry is possible, the stronger market conditions induce the creation of new firms producing new varieties. According to the 'home market effect', a change in demand for domestically produced goods raises the number of varieties more than proportionally, and/or raises domestic factor prices.
} 
by Debaere and Lee (2004) appears to corroborate these results: they show that productivity improvements induced by R\&D as well as an increase in a country's per capita GDP relative to its trading partners have a positive impact on the terms of trade. Since both measures are related to changing varieties in the theoretical and empirical literature, this suggests that fast output expansion need not necessarily imply a drop in a country's terms of trade. Faster relative output growth not induced by $\mathrm{R} \& \mathrm{D}$ has however a negative impact on terms of trade.

Our model also predicts that, ceteris paribus, countries with a larger market size (and therefore demand) supply a larger fraction of world goods, and have stronger terms of trade. Again, this prediction of the model is consistent with empirical evidence. The model suggests that output and consumption in these countries are high relative to the rest of the world, but their real exchange rate (appropriately measured as to account for product varieties) tends to be weaker. Analogously, when government spending is biased towards domestic goods, countries with a larger fiscal sector have higher GDP, appreciated terms of trade, but weaker real exchange rate. High public consumption is associated with high private consumption.

The international spillovers from domestic productivity gains and surges in demand depend in part on the sign and size of relative price movements. In general, foreign households are better off if they can buy imports at lower prices - the point stressed by traditional models of the international transmission. With endogenous patterns of production, however, another important determinant of welfare is consumers' taste for variety. Even if productivity gains in manufacturing in one country lower the international price of the goods supplied by that country's firms, our model points out that the number of varieties produced worldwide tend to fall as price competition drives down profits. Ultimately, foreign agents benefit from lower import prices, but they may be worse off overall due to the reduced availability of consumption varieties. Conversely, even if lower entry costs tend to raise the international price of a country's products, the associated rise in the number of varieties available to consumers worldwide may make foreign households better off - provided that their preference for product variety is strong enough.

Trade liberalization that reduces cross-border trade costs benefits consumers via lower prices (higher real incomes). However, our model also emphasizes that efficiency gains from deeper economic integration may result in a lower array of goods available to consumers. This raises the issue of whether world welfare could fall if consumers highly value variety a point often stressed in the debate on the effects of globalization. We will show that this is not the case: for any degree of love for varieties, our model predicts that the gains from 
lower prices are always larger that the costs associated with a possible contraction in the set of goods supplied world wide.

All goods are tradable in our model, so that our framework differs from both the traditional Balassa-Samuelson view and its re-interpretation by Ghironi and Melitz (2004). As in the latter contribution, we trace the implications of using price indices that fail to account for product varieties, providing examples in which inappropriate indices of the real exchange rate would provide misleading information. It is worth noting that in our model full tradability need not coincide with free trade. In fact, without frictions in international trade the real exchange rate would be constant in our setup, no deviation from PPP would ever appear, and the nature of productivity innovations would not matter.

Section 2 presents the model setup. Section 3 discusses its equilibrium properties. Section 4 analyzes productivity differentials. Section 5 studies asymmetries in market size, including the role of government spending. Section 6 uses numerical examples to shed light on welfare results. Section 7 concludes.

\section{The model}

The world economy consists of two countries, Home and Foreign - Foreign variables are denoted with a star. In each country there are households, firms, and a government.

Households consume a basket of differentiated tradable goods. They love variety of goods: they demand any 'brand' of both domestically produced and imported goods available in the market. They supply labor to domestic firms only but own claims on firms' profits worldwide. Labor is not mobile across borders. There are $L_{t}$ households in the Home country and $L_{t}^{*}$ households in the Foreign country.

Over the time frame relevant for analysis (period $t$ ), agents set up firms and create new varieties of goods. Firms in both countries produce goods for both domestic and export markets, using labor as the only input in production. The varieties produced by firms operating in the Home country are defined over a continuum of mass $n_{t}$ and indexed by $h \in\left[0, n_{t}\right]$. Similarly, Foreign varieties are indexed by $f \in\left[0, n_{t}^{*}\right]$.

The number of varieties produced in each country is endogenously determined in the model. There is free entry in the goods sector, but firms face fixed entry costs to start production of a particular variety. The entry costs consist of wages paid to the labor employed in setting up a firm. Firms in both countries operate under conditions of monopolistic competition, so that each firm produces one variety only. Hence, an increase in $n_{t}$ corresponds to both the introduction of new varieties in the Home country, and the creation of new Home firms. At the end of period $t$ the (human) capital invested in the creation of a specific 
variety fully depreciates and the production process restarts with new entry of firms.

Governments are assumed to purchase goods from national firms only. They finance their expenditures with lump-sum net taxes.

\subsection{Firms}

To produce final goods for the domestic and the export markets, firms have access to a linear technology in labor. The production function of the representative Home firm producing a specific variety $h$ is:

$$
Y_{t}(h)=\alpha_{t} \ell_{t}(h)
$$

where $Y(h)$ is the output of variety $h, \ell(h)$ is labor used in its production, and $\alpha_{t}$ is a country-specific labor productivity innovation that is common to all Home firms. Similarly, in the Foreign country we have:

$$
Y_{t}^{*}(f)=\alpha_{t}^{*} \ell_{t}^{*}(f)
$$

To start the production of a variety $h$ in the Home country, a firm needs to employ $1 / \nu_{t}$ units of Home labor. The firm thus faces a fixed cost $q(h)$ :

$$
q_{t}(h)=w_{t} / \nu_{t}
$$

where $w_{t}$ is the wage rate and $\nu_{t}$ is labor productivity in the activities required to start a firm. ${ }^{3}$ Similarly, the entry cost in the Foreign country is:

$$
q_{t}^{*}(f)=w_{t}^{*} / \nu_{t}^{*}
$$

Efficiency in setting up a firm does not necessarily coincide with productivity in manufacturing. Thus, in general $\alpha$ differs from $\nu$.

From the vantage point of a new firm, it is never profitable to produce a brand $h$ or $f$ already supplied by other firms, rather than introducing a new good variety. Hence in equilibrium firms are monopolistic suppliers of one good only. Variety $h$ is sold to domestic agents (both private and public) or exported to foreign households. Shipping goods abroad entails transportation 'iceberg' costs, denoted by $\tau$ and expressed in units of the export good. The resource constraint for variety $h$ is therefore:

$$
Y_{t}(h) \geq L_{t} C_{t}(h)+(1+\tau) L_{t}^{*} C_{t}^{*}(h)+G_{t}(h)
$$

\footnotetext{
${ }^{3}$ It would be possible to introduce alternative parameterizations of the entry costs, even though they would leave substantially unaltered our qualitative results. For instance, one could consider a convex entry cost as an increasing function of the overall number of varieties. In this case the Foreign entry cost would depend on the number of Home varieties, adding a negative international spillover to the analysis.
} 
where $C_{t}(h)$ is consumption of good $h$ by the representative Home resident, $C_{t}^{*}(h)$ is consumption of good $h$ by the representative Foreign resident, and $G_{t}(h)$ is Home government purchases of good $h$. Similarly, the resource constraint faced by the Foreign firm producing good $f$ is:

$$
Y_{t}^{*}(f) \geq L_{t}(1+\tau) C_{t}(f)+L_{t}^{*} C_{t}^{*}(f)+G_{t}^{*}(f)
$$

Let $p_{t}(h)$ denote the Home-currency price of one unit of good $h$ sold in the domestic market, and $p_{t}(f)$ the Home-currency price of imports $f$. Similarly $p_{t}^{*}(h)$ is the Foreigncurrency price of variety $h$ imported by the Foreign country and $p_{t}^{*}(f)$ is the Foreigncurrency price of variety $f$ sold in the Foreign country. Also, let $\varepsilon_{t}$ denote the nominal exchange rate, defined as Home currency per unit of Foreign currency. Using the above notation, Home-currency operating profits are:

$$
\Pi_{t}(h) \equiv p_{t}(h) L_{t} C_{t}(h)+\varepsilon_{t} p_{t}^{*}(h) L_{t}^{*} C_{t}^{*}(h)+p_{t}(h) G_{t}(h)-w_{t} \ell_{t}(h)
$$

Accounting for (5) and (1), the optimal prices $p_{t}(h)$ and $p_{t}^{*}(h)$ - charged by the Home firm to maximize its profits $(7)$ - solve:

$$
\begin{gathered}
1+\left(p_{t}(h)-\frac{w_{t}}{\alpha_{t}}\right) \frac{\partial\left(L_{t} C_{t}(h)+G_{t}(h)\right) / \partial p_{t}(h)}{L_{t} C_{t}(h)+G_{t}(h)}=0 \\
\varepsilon_{t}+\left(\varepsilon_{t} p_{t}^{*}(h)-\frac{w_{t}}{\alpha_{t}}(1+\tau)\right) \frac{\partial\left(L_{t}^{*} C_{t}^{*}(h)\right) / \partial p_{t}^{*}(h)}{L_{t}^{*} C_{t}^{*}(h)}=0 .
\end{gathered}
$$

Similar expressions hold for $\Pi_{t}^{*}(f), p_{t}(f)$ and $p_{t}^{*}(f)$.

\subsection{Households and government}

The utility of the representative national household is a positive function of consumption $C_{t}$ and a negative function of labor effort $\ell_{t}$. As household preferences are defined over a very large set of goods, utility is a well-defined (and non-decreasing) function of all goods available in the market. Focusing on Home country residents, utility in period $t$ is: ${ }^{4}$

$$
U_{t}=\frac{C_{t}^{1-\frac{1}{\psi}}}{1-\frac{1}{\psi}}-\kappa \ell_{t}
$$

where $C_{t}$ is a composite good that includes all varieties:

$$
C_{t}=A_{t}\left[\int_{0}^{n_{t}} C_{t}(h)^{1-\frac{1}{\sigma}} d h+\int_{0}^{n_{t}^{*}} C_{t}(f)^{1-\frac{1}{\sigma}} d f\right]^{\frac{\sigma}{\sigma-1}}
$$

\footnotetext{
${ }^{4}$ In our model we assume constant marginal disutility of labor, corresponding to an infinite Frisch elasticity of labor (the latter is defined as the elasticity of labor suppply relative to the wage, keeping constant the marginal utility of consumption). It can be shown that our results remain qualitatively unchanged under alternative specifications with a lower (finite) Frisch elasticity.
} 
and the term $A_{t}$ is defined as:

$$
A_{t} \equiv\left(n_{t}+n_{t}^{*}\right)^{\gamma-\frac{\sigma}{\sigma-1}}
$$

In the expressions above, the parameters $\psi$ and $\sigma$ denote, respectively, the elasticities of intertemporal and intratemporal (i.e., across varieties) substitution, with $\psi>0$ and $\sigma \geq 1$, and the parameter $\gamma$ measures the degree of consumers' love for variety. Precisely, as shown by Benassy (1996), $\gamma-1$ represents the marginal utility gain from spreading a given amount of consumption on a basket that includes one additional good variety.

Consumers' preferences for variety play an important role in our analysis, especially in determining the sign of international spillovers. Note that if we set $\gamma=\sigma /(\sigma-1)$, expression (11) would be equivalent to the standard Dixit-Stiglitz consumption index. In this case, the marginal utility of variety would be $1 /(\sigma-1)$, i.e. it would be strictly tied to elasticity of substitution $\sigma$ (which in equilibrium determines the size of the markups in the product market). However, there is no particular reason for adopting a welfare metrics based on an arbitrary and mechanical link between the elasticity of substitution among goods and individual preferences for goods variety. ${ }^{5}$ Our formulation allows for a separate treatment of these two dimensions of consumers' preferences.

The budget constraint for the representative Home household is:

$$
\int_{0}^{n_{t}} p_{t}(h) C_{t}(h) d h+\int_{0}^{n_{t}^{*}} p_{t}(f) C_{t}(f) d f+I_{t} \leq w_{t} \ell_{t}+\Pi_{t}-T_{t}
$$

where $T$ are lump-sum net taxes denominated in Home currency, $I_{t}$ is households' 'investment' in firms (financing entry costs) and $\Pi_{t}$ is total dividends revenue. We assume that markets are incomplete. Without loss of generality, we also posit that households are endowed with a well-diversified international portfolio of claims on firms' profits, so that they finance the same fraction of the cost of creating new varieties in each country. ${ }^{6}$ Formally, Home households invest in a diversified portfolio of firms:

$$
I_{t} \equiv \frac{1}{L_{t}+L_{t}^{*}}\left(\int_{0}^{n_{t}} q_{t}(h) d h+\varepsilon_{t} \int_{0}^{n_{t}^{*}} q_{t}^{*}(f)^{*} d f\right)
$$

In return, each Home household receives an equal share of profits of all firms in the world economy:

$$
\Pi_{t} \equiv \frac{1}{L_{t}+L_{t}^{*}}\left(\int_{0}^{n_{t}} \Pi_{t}(h) d h+\varepsilon_{t} \int_{0}^{n_{t}^{*}} \Pi_{t}^{*}(f) d f\right) .
$$

\footnotetext{
${ }^{5}$ This is discussed in the working paper version (1974) of Dixit and Stiglitz (1977), as well as by Benassy (1996).

${ }^{6}$ This is in contrast with the standard assumption that households only own and finance domestic firms. As long as free entry is assumed, positing complete home bias in equity portfolio would not alter our results.
} 
The representative Home household maximizes (10) with respect to $C_{t}(h), C_{t}(f)$, and $\ell_{t}$ subject to (13). The first order conditions yield:

$$
\begin{gathered}
C_{t}(h)=A_{t}^{\sigma-1}\left(\frac{p_{t}(h)}{P_{t}}\right)^{-\sigma} C_{t} \\
C_{t}(f)=A_{t}^{\sigma-1}\left(\frac{p_{t}(f)}{P_{t}}\right)^{-\sigma} C_{t} \\
w_{t}=\kappa P_{t} C_{t}^{1 / \psi}
\end{gathered}
$$

where $P_{t}$ is the utility-based consumer price index:

$$
P_{t}=\frac{1}{A_{t}}\left[\int_{0}^{n_{t}} p_{t}(h)^{1-\sigma} d h+\int_{0}^{n_{t}^{*}} p_{t}(f)^{1-\sigma} d f\right]^{\frac{1}{1-\sigma}}
$$

Without loss of generality, in what follows we choose the appropriate nominal units of account such that $w_{t}=\kappa$, so that:

$$
C_{t}=P_{t}^{-\psi}
$$

As domestic households provide labor in a competitive market both for firms' start-up and production activities, the resource constraint in the Home labor market is:

$$
L_{t} \ell_{t} \geq \int_{0}^{n_{t}} \frac{Y_{t}(h)}{\alpha_{t}} d h+\frac{n_{t}}{\nu_{t}}
$$

Similar expressions hold in the Foreign country.

We posit that the governments spend only on local varieties and balance their budgets every period. The Home government budget constraint is therefore:

$$
\int_{0}^{n_{t}} p_{t}(h) G_{t}(h) d h=L_{t} T_{t}
$$

For simplicity, we assume that public demand for each specific variety has the same price elasticity $\sigma$ as private demand, so that:

$$
G_{t}(h)=\left(\frac{p_{t}(h)}{P_{G, t}}\right)^{-\sigma} G_{t}, \quad G_{t}^{*}(f)=\left(\frac{p_{t}^{*}(f)}{P_{G, t}^{*}}\right)^{-\sigma} G_{t}^{*}
$$

where $G_{t}$ and $G_{t}^{*}$ denote total public consumption in the two countries and $P_{G}$ and $P_{G}^{*}$ are government spending deflators which involve only prices of domestically-produced varieties: ${ }^{7}$

$$
P_{G, t}=\left[\frac{1}{n_{t}} \int_{0}^{n_{t}} p_{t}(h)^{1-\sigma} d h\right]^{\frac{1}{1-\sigma}}, \quad P_{G, t}^{*}=\left[\frac{1}{n_{t}^{*}} \int_{0}^{n_{t}^{*}} p_{t}^{*}(f)^{1-\sigma} d f\right]^{\frac{1}{1-\sigma}}
$$

\footnotetext{
${ }^{7}$ This specification deliberately assumes that governments do not care about variety, that is, the parameter $\gamma$ in public preferences in equal to one. This has no first-order impact on our results as long as we analyze shocks around an initial equilibrium where government expenditures are zero.
} 


\section{$2.3 \quad$ Prices}

Substituting expressions (16), (17), (23) and their Foreign analogs in (8) and (9), we derive the prices charged by Home firms as markups over marginal costs, equal in our setup to labor costs per unit of product:

$$
\begin{aligned}
p_{t}(h) & =\frac{\sigma}{\sigma-1} \frac{w_{t}}{\alpha_{t}} \equiv p_{t} \\
\varepsilon_{t} p_{t}^{*}(h) & =\frac{\sigma}{\sigma-1} \frac{w_{t}}{\alpha_{t}}(1+\tau)=p_{t}(1+\tau)
\end{aligned}
$$

Similar expressions hold in the Foreign country:

$$
\begin{aligned}
& p_{t}^{*}(f)=\frac{\sigma}{\sigma-1} \frac{w_{t}^{*}}{\alpha_{t}^{*}} \equiv p_{t}^{*} \\
& \frac{p_{t}(f)}{\varepsilon_{t}}=\frac{\sigma}{\sigma-1} \frac{w_{t}^{*}}{\alpha_{t}^{*}}(1+\tau)=p_{t}^{*}(1+\tau)
\end{aligned}
$$

Note that productivity gains (higher $a_{t}$ or $\alpha_{t}^{*}$ ) lower marginal costs and reduce product prices proportionally.

The equilibrium utility-based Consumer Price Indices (CPIs) are defined as the minimum expenditures required to purchase one unit of the baskets $C$ and $C^{*}$, and are equal to:

$$
P_{t}=p_{t} B_{t}^{\frac{1}{1-\sigma}} / A_{t}, \quad P_{t}^{*}=p_{t}^{*} B_{t}^{* \frac{1}{1-\sigma}} / A_{t}
$$

where:

$$
B_{t} \equiv n_{t}+n_{t}^{*} \phi\left(\varepsilon_{t} p_{t}^{*} / p_{t}\right)^{1-\sigma}, \quad B_{t}^{*} \equiv n_{t}^{*}+n_{t} \phi\left(\varepsilon_{t} p_{t}^{*} / p_{t}\right)^{\sigma-1},
$$

and, borrowing a familiar notation from the international trade literature, $\phi \equiv(1+\tau)^{1-\sigma}$. The parameter $\phi$ is positive and less than one; the case $\phi=0$ corresponds to infinite trade costs and the case $\phi=1$ to zero trade costs. Finally, as governments spend only on domestic varieties, in equilibrium the public consumption indices $P_{G}$ and $P_{G}^{*}$ are simply:

$$
P_{G, t}=p_{t}, \quad P_{G, t}^{*}=p_{t}^{*}
$$

\section{Firms' profits and product varieties in the global econ- omy}

\subsection{Free entry and the balance of payments}

In this section we characterize the model solution, and comment on the equilibrium link between profits and the creation of new varieties. To start with, using (16), (17), (20), and (29), we can write the operating profits earned by imperfectly competitive firms as follows: ${ }^{8}$

$$
\Pi_{t}(h)=A_{t}^{1-\sigma} \frac{p_{t}^{1-\psi}}{\sigma}\left[\frac{L_{t}}{B_{t}^{\frac{\sigma-\psi}{\sigma-1}}}+\frac{L_{t}^{*} \phi \varepsilon_{t}^{\sigma}\left(p_{t}^{*} / p_{t}\right)^{\sigma-\psi}}{B_{t}^{* \frac{\sigma-\psi}{\sigma-1}}}\right]+\frac{p_{t}}{\sigma} G_{t} \equiv \pi_{t}
$$

\footnotetext{
${ }^{8}$ The private individual demands for the $h$ and $f$ goods in the Home country are:
} 


$$
\Pi_{t}^{*}(f)=A_{t}^{1-\sigma} \frac{p_{t}^{* 1-\psi}}{\sigma}\left[\frac{L_{t}^{*}}{B_{t}^{* \frac{\sigma-\psi}{\sigma-1}}}+\frac{L_{t} \phi \varepsilon_{t}^{-\sigma}\left(p_{t}^{*} / p_{t}\right)^{\psi-\sigma}}{B_{t}^{\frac{\sigma-\psi}{\sigma-1}}}\right]+\frac{p_{t}^{*}}{\sigma} G_{t}^{*} \equiv \pi_{t}^{*}
$$

where $\pi$ and $\pi^{*}$ denote firms' profits in their own currencies. Note that with constant markups, we can express the profits of the representative firm in both countries as a constant fraction $1 / \sigma$ of global sales.

With strictly positive trade costs (i.e., $\phi<1$ ), we can use the expressions for profits to shed light on some crucial dimensions of the transmission mechanism further studied below. First, holding the number of varieties and relative prices constant, an increase in Home market size (an increase in $L$ ) raises operating profits at Home more than abroad. This is the 'Home market effect' analyzed in trade models. Second, everything else constant, an increase in the number of Home firms lowers Home profits more than Foreign profits. This is because trade costs partially shield Foreign firms from competition by Home firms. Third, holding the number of Foreign and Home goods constant, a depreciation of the Home currency (an increase in $\epsilon$ ) raises profits at Home. This is the 'competitive effect' of real depreciations: Home-produced goods become cheaper, and their demand increases. Finally, for a given exchange rate and number of firms, a productivity innovation in the manufacturing sector at Home (an increase in $\alpha$ ) corresponds to a drop in $p^{*} / p$, with opposite effects on Home profits. By charging lower prices, Home firms become relatively more competitive and experience an increase in sales. However, because all Home firms experience the same rise in productivity, and charge the same lower price, when the intertemporal elasticity of substitution is less than one, sales revenue decreases overall. ${ }^{9}$

With free entry, optimal investment in new varieties implies that the value of a firm is equal to the cost of creating a variety, and in equilibrium this must be equal to the value of operating profits. Thus competition in the goods market implies the following free entry

$$
\begin{aligned}
& C_{t}(h)=A_{t}^{\sigma-1} P_{t}^{\sigma-\psi} p_{t}^{-\sigma}=A_{t}^{\psi-1} p_{t}^{-\psi} B_{t}^{-\frac{\sigma-\psi}{\sigma-1}} \text { and } \\
& C_{t}(f)=A_{t}^{\sigma-1} P_{t}^{\sigma-\psi}\left(\varepsilon_{t} p_{t}^{*}(1+\tau)\right)^{-\sigma}=A_{t}^{\psi-1}(1+\tau)^{-\sigma}\left(\varepsilon_{t} p_{t}^{*} / p_{t}\right)^{-\sigma} p_{t}^{-\psi} B_{t}^{-\frac{\sigma-\psi}{\sigma-1}} . \\
& \text { Similarly, in the Foreign country: } \\
& C_{t}^{*}(f)=A_{t}^{\sigma-1} P_{t}^{* \sigma-\psi} p_{t}^{*-\sigma}=A_{t}^{\psi-1} p_{t}^{*-\psi} B_{t}^{*-\frac{\sigma-\psi}{\sigma-1}} \text { and } \\
& C_{t}^{*}(h)=A_{t}^{\sigma-1} P_{t}^{* \sigma-\psi}\left(p_{t}(1+\tau) / \varepsilon_{t}\right)^{-\sigma}=A_{t}^{\psi-1}(1+\tau)^{-\sigma}\left(\varepsilon_{t} p_{t}^{*} / p_{t}\right)^{\sigma} p_{t}^{*-\psi} B_{t}^{*-\frac{\sigma-\psi}{\sigma-1}} .
\end{aligned}
$$

${ }^{9}$ One may conjecture that these results depend on the assumption of infinite Frisch elasticity. As labor supply becomes more inelastic, domestic agents may take advantage of productivity gains in manufacturing by increasing the array of goods supplied by domestic firms (hence by creating new firms). Notably, this is not the case: with a less elastic labor supply, the effect of higher manufacturing productivity on the global number of varieties is weaker, but remains negative as long as the intertemporal elasticity of substitution $\psi$ is less than 1. 
conditions:

$$
\begin{aligned}
q_{t} & =\frac{\kappa}{\nu_{t}}=\pi_{t} \\
q_{t}^{*} & =\frac{\kappa}{\nu_{t}^{*}}=\pi_{t}^{*}
\end{aligned}
$$

It follows that, in equilibrium, a fall in entry costs must translate into a corresponding fall in operating profits. When $\phi<1$, the mechanism of adjustment requires a rise in the number of varieties supplied by domestic firms, driving profits down. Note also that, as profits are proportional to global sales, the level of entry costs pins down firms' size. Using this result, we can write the size of each firm as a function of productivity levels $\alpha$ and $\nu$ as well as the elasticity $\sigma$ :

$$
Y_{t}(h)=(\sigma-1) \alpha_{t} / \nu_{t}
$$

It follows that Home GDP per capita can be written simply as $w_{t} \ell_{t}=\sigma \kappa n_{t} /\left(L_{t} \nu_{t}\right)$, and Home employment per capita is $\ell_{t}=\sigma n_{t} /\left(L_{t} \nu_{t}\right)$. These expressions will be useful in the analysis to follow.

Aggregating private and public budget constraints in any of the two countries, we can write the balance of payments in terms of Home currency as follows:

$$
\begin{gathered}
\phi A_{t}^{\psi-1}\left[\frac{p_{t}^{1-\psi} n_{t} L_{t}^{*} \varepsilon_{t}^{\sigma}\left(p_{t}^{*} / p_{t}\right)^{\sigma-\psi}}{B_{t}^{* \frac{\sigma-\psi}{\sigma-1}}}-\frac{p_{t}^{* 1-\psi} n_{t}^{*} L_{t} \varepsilon_{t}^{1-\sigma}\left(p_{t}^{*} / p_{t}\right)^{\psi-\sigma}}{B_{t}^{\frac{\sigma-\psi}{\sigma-1}}}\right] \\
-\frac{L_{t}^{*} \pi_{t} n_{t}}{L_{t}+L_{t}^{*}}+\frac{L_{t} \varepsilon_{t} \pi_{t}^{*} n_{t}^{*}}{L_{t}+L_{t}^{*}}+\frac{L_{t}^{*} q_{t} n_{t}}{L_{t}+L_{t}^{*}}-\frac{L_{t} \varepsilon_{t} q_{t}^{*} n_{t}^{*}}{L_{t}+L_{t}^{*}}=0
\end{gathered}
$$

The first two terms are Home exports less Home imports, both inclusive of trade costs their difference is therefore the trade balance. The third term corresponds to net profits paid by Home firms to Foreign households, the fourth term to net profits paid by Foreign firms to Home households - their difference representing net factor payments. The balance of these four terms is the current account. The sum of the last two terms is the capital account, i.e. the financing of Home firms by Foreign households minus the financing of Foreign firms by Home agents.

Using the balance of payment equilibrium (37), the two free entry conditions (34) and (35), as well as the equations for profits (32) and (33), it can be checked that equilibrium profits are:

$$
\begin{aligned}
\pi_{t} & =\frac{\kappa}{\nu_{t}}=\frac{L_{t}}{\sigma n_{t}} P_{t}^{1-\psi}+\frac{1}{\sigma} p_{t} G_{t} \\
\pi_{t}^{*} & =\frac{\kappa}{\nu_{t}^{*}}=\frac{L_{t}^{*}}{\sigma n_{t}^{*}} P_{t}^{* 1-\psi}+\frac{1}{\sigma} p_{t}^{*} G_{t}^{*}
\end{aligned}
$$

where $P_{t}^{1-\psi}=P_{t} C_{t}$ is total domestic expenditure. 
The above expressions highlight that an increase in the number of varieties has two effects on profits via consumption demand. On the one hand, it leads to a fall in the price of current consumption $P_{t}$ (as defined in (29)) by $1-\gamma$, the marginal welfare gain of goods diversity. The fall in the price index induces intertemporal substitution into current consumption by $(\psi-1)(\gamma-1)$, raising demand and profits. On the other hand, an increase in the number of goods implies intratemporal substitution away from existing goods, measured by -1 , with a negative effect on demand. The net effect is therefore given by $\psi \gamma-\gamma-\psi$.

Choosing a benchmark value for $\gamma$ is not obvious, as we are not aware of any empirical/quantitative work on the subject. However, the assumption that consumers value diversity, that is, $\gamma>1$, is not very strong. When $\gamma>1$, an increase in the number of goods does lower current consumption — and therefore lowers sales and profits — if $\psi$ $<\gamma /(\gamma-1)$. A sufficient condition for such inequality to hold is that the intertemporal elasticity of substitution $\psi$ is no larger than 1 - corresponding to benchmark values to be found in the literature, whereas the intertemporal elasticity of substitution $\psi$ is usually set between 1 and $1 / 2$. In the rest of the paper, unless otherwise stated, we will carry out our analysis under the maintained assumption that: $\psi \leq 1<\gamma \cdot{ }^{10}$

\subsection{Implications of trade reforms}

Recalling that $q_{t}=\kappa / \nu_{t}, q_{t}^{*}=\kappa / \nu_{t}^{*}, p_{t}=\sigma(\sigma-1)^{-1} \kappa \alpha_{t}^{-1}$ and $p_{t}^{*}=\sigma(\sigma-1)^{-1} \kappa \alpha_{t}^{*-1}$, the system of three equations (34), (35) and (37) determine the three endogenous variables $\varepsilon_{t}, n_{t}$ and $n_{t}^{*}$ as a function of the exogenous variables $\nu_{t}, \nu_{t}^{*}, \alpha_{t}, \alpha_{t}^{*}, L_{t}, L_{t}^{*}, G_{t}$ and $G_{t}^{*}$ for given parameters $\sigma, \psi, \kappa, \gamma$ and $\phi$. It is straightforward to verify that if $\nu_{t}=\nu_{t}^{*}=\alpha_{t}=$ $\alpha_{t}^{*}=L_{t}=L_{t}^{*}=1$ and $G_{t}=G_{t}^{*}=0$, there is a symmetric equilibrium such that $\varepsilon_{t}=1$ and $n_{t}=n_{t}^{*}$. In what follows, we take this equilibrium as the baseline in our comparative statics exercises. This symmetric equilibrium is characterized as follows: $p=p^{*}=\sigma \kappa /(\sigma-1)$, $w=w^{*}=\kappa, \ell=\ell^{*}=\sigma n$. Note also that: $P^{1-\psi}=P^{* 1-\psi}=n \sigma \kappa$. The number of varieties produced by each country is:

$$
n^{\psi+\gamma-\gamma \psi}=2^{(\psi-1)\left(\gamma-\frac{\sigma}{\sigma-1}\right)}(\kappa \sigma)^{-\psi}(\sigma-1)^{(\psi-1)}(1+\phi)^{(\psi-1) /(\sigma-1)}
$$

This expression suggests an interesting result on the effects of trade liberalization, defined as lower trade costs — which in our model correspond to a higher $\phi$. Namely, when the intertemporal elasticity of substitution is less than one, trade liberalization actually reduces the number of varieties supplied at the world level. This contrasts with the prediction of

\footnotetext{
${ }^{10}$ In the standard Dixit-Stiglitz model where $\gamma=\sigma /(\sigma-1)$, the condition is $\sigma>1>\psi$. Intuitively, this implies that goods are substitutes in the Edgeworth-Pareto sense.
} 
the standard Krugman model with trade-induced variety expansion. Recently, Baldwin and Forslid (2004) have discussed a similar result in a model with firms heterogeneity after Melitz (2003). The above expression however makes it clear that the fall in good varieties after liberalization does not depend on firms' heterogeneity.

In general, trade liberalization has two opposite effects: on the one hand it raises demand for goods, increases profits and therefore induces entry. This effect of raising $\phi$ is captured by the numerator of the expression (32) for Home profits. On the other hand, trade liberalization (if symmetric on both imports and exports) induces more competition by firms abroad. This effect is captured by the presence of $\phi$ in the terms at the denominator of equation (32). The number of varieties produced and traded by Home firms falls with trade liberalization when (a) $\psi<\gamma /(\gamma-1)$, so that profits are decreasing in the number of varieties and (b) $\psi<1$, so that the decrease in the price index induced by trade liberalization does not lead to a large jump in current consumption.

\section{Domestic and international implications of produc- tivity differentials}

In this and the following sections, we analyze the mechanism of international transmission with endogenous product varieties, by differentiating the equilibrium conditions (34), (35) and (37) around a symmetric equilibrium. We consider only 'shocks' to Home exogenous variables, with the understanding that similar results hold with respect to changes in Foreign variables.

Consider first the determinants of the overall number of varieties available to households worldwide:

$$
[\psi+\gamma(1-\psi)] \frac{d n_{t}+d n_{t}^{*}}{n}=d L_{t}+\frac{1}{\sigma-1} \frac{d G_{t}}{n}-(1-\psi) d \alpha_{t}+d \nu_{t}
$$

The number of varieties in the global economy unambiguously rises with a larger Home market size, higher Home government spending on Home goods, and gains in efficiency in setting up firms and creating new goods in the Home country. Notably, the effects

of gains in manufacturing productivity depend on the size of the intertemporal elasticity of substitution: the global number of varieties falls when $\psi<1$, rises otherwise. We will discuss the intuition underlying this result below. For the time being, it is worth noting that a productivity innovation that affects both manufacturing costs and entry costs symmetrically, i.e. $d \alpha_{t}=d \nu_{t}$, unambiguously leads to entry. Also, other things equal, exchange rate movements do not affect the global number of varieties: in our symmetric world economy, changes in the exchange rate affect symmetrically — but with opposite sign 
- sales and profits in both countries, without global effects.

One may reasonably expect that countries with higher productivity be the world suppliers of most good varieties, sold abroad at a relatively low international price. In what follows, we will show that this is not necessarily the case. A crucial issue in this respect is the distinction between productivity in manufacturing, and efficiency gains reducing the costs of setting up firms and introducing new varieties.

In our framework, countries with higher productivity in manufacturing actually charge lower international prices (i.e., their terms of trade deteriorate), but supply a smaller (not a larger) set of goods to world markets. This is because higher competition in the product market drives goods prices and Home suppliers' profits down. For a given cost of setting up a firm, lower goods prices and profits lead to market exit. Such competition effect is somewhat muted abroad, to the extent that Foreign firms are shielded by trade costs.

Conversely, gains in efficiency related to innovation and firms creation improve a country's terms of trade, and raise the number of varieties, both domestically and globally. In this case higher productivity does not spur more intensive competition in a given set of goods markets, but leads firms to compete by expanding the array of goods and services provided. Intuitively, introducing a new good when agents prefer varieties implies that demand rises in line with supply. More efficient countries will thus be able to expand their exports, without suffering a deterioration of their terms of trade. In the Foreign country, more competition by Home firms can be partly offset by higher global demand. The net effect on entry and employment is therefore ambiguous.

\subsection{Productivity gains in manufacturing}

We first focus on gains in manufacturing productivity by the Home country, i.e. an increase in $\alpha$. We have already seen in (41) that, as long as $\psi<1$, gains in Home manufacturing productivity reduce the number of goods produced worldwide. Their implications for the international allocation of production are summarized by the following expressions:

$$
\begin{aligned}
& \frac{1}{n} \frac{d n_{t}}{d \alpha_{t}}=-\frac{1-\psi}{2[\psi+\gamma(1-\psi)]}-\frac{(\sigma-1)(1-\psi)}{2(\sigma-\psi)}\left[1-\frac{2 \psi(\sigma-1) \phi}{\Delta}\right]<0 \\
& \frac{1}{n} \frac{d n_{t}^{*}}{d \alpha_{t}}=-\frac{1-\psi}{2[\psi+\gamma(1-\psi)]}+\frac{(\sigma-1)(1-\psi)}{2(\sigma-\psi)}\left[1-\frac{2 \psi(\sigma-1) \phi}{\Delta}\right]
\end{aligned}
$$

where:

$$
\Delta=(2 \sigma-1)[\sigma-\psi(1-\phi)]-\sigma \phi>0 .
$$

Gains in Home manufacturing productivity unambiguously reduce the number of varieties supplied by Home firms, although their scale of production rises (see (36)). The effect on the number of Foreign firms is ambiguous. It is negative in the Dixit-Stiglitz case, 
$\gamma=\sigma /(\sigma-1)$, or when trade costs are low enough, as strong competition by Home firms greatly reduces Foreign producers' profits. In any case, it can be verified that the number of varieties always falls more at Home than in the Foreign country.

To shed light on these results, it is useful to contrast their micro and macro dimensions. From the vantage point of an individual Home firm, productivity gains that reduce the marginal costs of production are an opportunity for firms to expand their market share and profits via a reduction in the price of their products. However, with an economy-wide productivity innovation, all Home firms simultaneously experience the same fall in marginal costs: they all compete with each other by cutting prices. As discussed above, a fall in the price of consumption affects aggregate consumption demand with elasticity $\psi$. When this elasticity is below one, lower prices translate into lower profits for the Home firms. For given entry costs, lower profits reduce the number of varieties produced by Home firms. Conversely, when $\psi>1$, a fall in prices raises demand more than proportionally, driving up profits and therefore the number of varieties supplied in equilibrium. There is no change in Home varieties when $\psi=1 .^{11}$

Since we scale nominal variables by equating wage rate to the constant parameter $\kappa$, nominal exchange rate movements index the relative price of labor. Our first result is that Home labor becomes more expensive - the nominal exchange rate appreciates - in response to productivity innovations:

$$
\frac{d \varepsilon_{t}}{d \alpha_{t}}=-\frac{[(\sigma-\psi)(1-\phi)+(\sigma-1)(1+\phi)](\sigma-1)}{\Delta}<0 .
$$

Note that the effect is stronger, the higher the trade costs.

Nonetheless, the terms of trade deteriorate. Defining $T O T_{t} \equiv p_{t} /\left(p_{t}^{*} \varepsilon_{t}\right)$, we have:

$$
\frac{d T O T_{t}}{d \alpha_{t}}=-1-\frac{d \varepsilon_{t}}{d \alpha_{t}}<0
$$

Even if Home labor is relatively more expensive than Foreign labor, marginal costs and therefore the price of domestic goods fall with productivity gains, more than offsetting the nominal exchange rate appreciation. It can also be checked that with zero trade costs (i.e. when $\phi$ approaches 1) it must be the case that $d T O T_{t} / d \alpha_{t}=-1 / \sigma$.

Let $R E R$ denote the welfare-based real exchange rate, i.e., $R E R_{t} \equiv \varepsilon_{t} P_{t}^{*} / P_{t}$. The real exchange rate also depreciates, moving in the opposite direction relative to the nominal

\footnotetext{
${ }^{11}$ In our model, all firms supply goods to both the domestic and the foreign markets, hence entry and exit at national level correspond one-to-one to entry and exit in the export markets. Allowing for firm-specific productivities (as in Ghironi and Melitz (2004)) introduces the possibility that some good be endogenously non-traded in equilibrium, depending on prices and productivity levels. In this case, entry and exit in the export markets may differ from entry and exit of firms located in the Home country. What our analysis highlights is the aggregate effect on total supply, which is sometimes blurred in analyses stressing heterogeneity.
} 
exchange rate:

$$
\frac{1}{R E R} \frac{d R E R_{t}}{d \alpha_{t}}=\frac{\psi(1-\phi)(\sigma-1)}{\Delta}>0
$$

In other words, movements in the real exchange rate are dominated by the relative movement of price indices (rather than by the movement in the nominal exchange rate). In the Home market, the welfare-based price index falls in response to productivity gains in manufacturing:

$$
\frac{1}{P} \frac{d P_{t}}{d \alpha_{t}}=\frac{1}{1-\psi} \frac{1}{n} \frac{d n_{t}}{d \alpha_{t}}<0
$$

This result is due both to a fall in the price of domestic goods and import prices (the latter because of exchange rate appreciation), and to the direct impact of an increase in goods variety on the welfare-based price index.

Symmetrically, the response of the welfare-based price index in the Foreign country to changes in $\alpha$ is:

$$
\frac{1}{P} \frac{d P_{t}^{*}}{d \alpha_{t}}=\frac{1}{1-\psi} \frac{1}{n} \frac{d n_{t}^{*}}{d \alpha_{t}}
$$

The sign here is generally ambiguous, but we note that $P_{t}^{*}$ decreases when trade costs and/or love for variety are sufficiently low ( $\phi$ is high, $\gamma$ is low enough). Intuitively, with low trade costs, stronger competition by more efficient Home firms drives down goods prices and causes exit in the Foreign market. The overall effect is a drop in the CPI, unless variety is strongly preferred by consumers.

Recent literature has emphasized potential measurement problems that arise when consumption baskets are not properly constructed so to account for (endogenous) changes in the number of goods varieties (see Feenstra (1994) and Broda and Weinstein (2004a,b) among others). Ghironi and Melitz (2004) carry out a numerical assessment of the gap between theoretically-consistent real exchange rates, and what they dub 'empirical exchange rates' - based on price indices that simply average prices over a fixed bundle of varieties. In the same spirit, we set $d n_{t} / d \alpha_{t}=d n_{t}^{*} / d \alpha_{t}=0$ in the above expressions, and denote the resulting price index at Home and abroad with $\widetilde{P}_{t}$ and $\widetilde{P}_{t}^{*}$, respectively. If we used these price indices in computing the real exchange rate (that is, defining $\widetilde{R E R}+\equiv \varepsilon_{t} \widetilde{P}_{t}^{*} / \widetilde{P}_{t}$ ), the effect of a productivity innovation would still be a depreciation, but at a lower rate:

$$
\frac{1}{\widetilde{R E R}} \frac{d \widetilde{R E R_{t}}}{d \alpha_{t}}=\frac{1-\phi}{1+\phi}\left(1+\frac{d \varepsilon_{t}}{d \alpha_{t}}\right)>0
$$

We conclude by noting that without trade costs, i.e. with $\phi=1$, the real exchange rate (independently of the CPI definition) would always be constant, i.e., PPP would hold. But trade costs generate home bias in consumption, thus productivity differences induce deviations from PPP despite the fact that in our framework all goods are traded. 


\subsection{Efficiency gains in creating new firms and new goods}

Consider now the effects of productivity gains that reduce costs in the activities at the origin of new firms and varieties. An analysis of this type of effects is obviously absent in standard models without entry, whereas productivity is confined to the manufacturing sector.

We have seen in equation (41) above that lower entry costs raise the number of varieties supplied at the global level. But the worldwide distribution of varieties clearly changes. The country-specific effects of changes in the level of $\nu$ are given by:

$$
\begin{aligned}
\frac{1}{n} \frac{d n_{t}}{d \nu_{t}} & =\frac{1}{2[\psi+\gamma(1-\psi)]}+\frac{(\sigma-1)}{2(\sigma-\psi)}\left[1+\frac{2 \psi \phi(1-\psi)}{\Delta}\right]>0 \\
\frac{1}{n} \frac{d n_{t}^{*}}{d \nu_{t}} & =\frac{1}{2[\psi+\gamma(1-\psi)]}-\frac{(\sigma-1)}{2(\sigma-\psi)}\left[1+\frac{2 \psi \phi(1-\psi)}{\Delta}\right]
\end{aligned}
$$

The first expression is unambiguously positive: more goods are produced by the Home country. In the Foreign country, instead, the effect is generally ambiguous. It can be verified that the number of varieties supplied by Foreign firms decreases in the Dixit-Stiglitz case, $\gamma=\sigma /(\sigma-1)$, or when trade costs are low enough. Trade integration (a higher $\phi$ ) amplifies the effect of lower entry costs on the Home supply of varieties. This is because new entry at Home raises competition worldwide, the more so the lower trade costs. With low trade costs, competition by Home producers unambiguously drives Foreign firms' profits down.

To analyze the equilibrium response of relative prices, we first observe that marginal costs and therefore $p$ and $p^{*}$ are not affected by $\nu_{t}$. The Home nominal exchange rate, however, strengthens:

$$
\frac{d \varepsilon_{t}}{d \nu_{t}}=-\frac{(\sigma-\psi)(1-\phi)+(\sigma-1)(1+\phi)}{\Delta}<0 .
$$

Given $p$ and $p^{*}$, the terms of trade move one-to-one with the nominal exchange rate: the country with lower costs of entry experiences an equilibrium appreciation of the terms of trade. The response of the nominal exchange rate is stronger, the higher trade costs are this is so because high trade costs raise the rate of appreciation required to bring about the equilibrium change in relative demand for goods.

Although both the nominal exchange rate and the terms of trade become stronger, the welfare-based real exchange rate actually depreciates:

$$
\frac{1}{R E R} \frac{d R E R_{t}}{d \nu_{t}}=\frac{\psi(1-\phi)}{\Delta}>0
$$

The weakening of the real exchange rate is entirely due to the increase in the number of varieties, reflecting the important property of welfare-based price indices discussed above: a wider array of varieties per se reduces the CPI. 
It follows that, when productivity affects the cost of creating new varieties, the sign of our comparative statics results will crucially depend on which measure of real exchange rate is used, i.e. whether this is the welfare-based $R E R$ or the 'empirically relevant' $\widetilde{R E R}$. In fact, a measure of the real exchange rate based on price indices that fail to account for changes in the number of varieties would move in the opposite direction relative to the welfare-based real exchange rate, i.e., it would point to a real exchange rate appreciation:

$$
\frac{1}{\widetilde{R E R}} \frac{d \widetilde{R E R}}{d \nu_{t}}=\frac{1-\phi}{1+\phi} \frac{d \varepsilon_{t}}{d \nu_{t}}<0
$$

The use of an inappropriate index would thus provide severely biased information.

In the Home market, the response of the welfare-based CPI to changes in $\nu_{t}$ is negative:

$$
\frac{1}{P} \frac{d P_{t}}{d \nu_{t}}=\frac{1}{1-\psi}\left(\frac{1}{n} \frac{d n_{t}}{d \nu_{t}}-1\right)<0 .
$$

Import prices fall with a stronger currency. The higher availability of product varieties also reduces the welfare-based price index. The response of the CPI in the Foreign country is instead ambiguous:

$$
\frac{1}{P} \frac{d P_{t}^{*}}{d \nu_{t}}=\frac{1}{1-\psi} \frac{1}{n} \frac{d n_{t}^{*}}{d \nu_{t}}
$$

Once again, the Foreign price index falls when trade costs and/or love for variety are sufficiently low ( $\phi$ is high, $\gamma$ is high enough). In these cases Foreign consumers face higher import prices, but the adverse terms of trade effects on the welfare-based price index is more than compensated by a higher array of goods - resulting in a lower CPI.

\subsection{A comparison}

We have seen above that improvements in productivity in Home manufacturing, and asymmetric efficiency gains reducing Home entry costs relative to Foreign costs have quite different equilibrium implications. Consider for instance the comovements in GDP per capita and relative prices predicted by the model. Since the ratio of Home to Foreign GDP per capita can be written as: $L_{t}^{*} \nu_{t}^{*} n_{t} /\left(\varepsilon_{t} L_{t} \nu_{t} n_{t}^{*}\right)$, it is easy to verify that relative GDP is increasing in both $\alpha_{t}$ and $\nu_{t}$. However, a rise in Home GDP relative to Foreign GDP may be associated with either an appreciation or a depreciation of the real exchange rate - depending on which type of innovation takes place. Predictions reminiscent of Balassa-Samuelson richer countries have a stronger real exchange rate - are generated by innovations to $\nu$, but only if price indices are not properly adjusted for changes in product varieties. In this case, the (empirically relevant) exchange rate would unambiguously appreciate with a rise in relative GDP driven by higher productivity in creating firms and new goods. 
Most crucially, the implications for the terms of trade are widely different: the terms of trade deteriorate in response to an increase in productivity that lowers marginal costs in production, while improves if productivity gains reduce the cost of firms' entry. The latter effect dominates if $d \alpha_{t}=d \nu_{t} \cdot{ }^{12}$ These results question the standard prediction that higher growth rates lead to deteriorating the terms of trade.

Distinguishing between $\alpha$-type and $\nu$-type productivities is a difficult and challenging empirical task. Recent empirical studies have appealed to the intuition in Krugman (1989), and attempted to measure the effect on the terms of trade of an increase in the supply of goods, as opposed to an increase in the varieties of goods supplied in the world markets. In a quite elaborated panel study, Debaere and Lee (2004) indeed find a positive association between higher spending in $R \& D$ and stronger terms of trade. In this respect, the model in this paper provides a theoretical framework to conceptualize and motivate similar empirical exercises. ${ }^{13}$

\section{Asymmetries in market size}

In this section we analyze the implications of market size, revisiting some results of the trade literature on the 'Home market effect.' In its original formulation that can be traced back to Krugman (1980), the 'Home market effect' represents the more-than-proportional impact of an increase in market size on the number of varieties produced domestically, in the presence of trade costs and holding labor supply and real exchange rate constant. In what follows we cast the analysis of market size asymmetries - here measured by $L_{t} / L_{t}^{*}$-in the context of our general-equilibrium analysis with endogenous international prices and labor supply. Next, we compare these results with the effects of asymmetries in government spending across countries.

\subsection{Labor force and private expenditure}

Consider first the general-equilibrium implications of a relatively larger Home market on the number of varieties produced worldwide and in each country. Equation (41) above shows that an increase in $L_{t}$ raises the number of varieties supplied at the global level. The

\footnotetext{
${ }^{12}$ In this case, the terms of trade improve by $\psi(\sigma-1)(1-\phi) / \Delta$.

${ }^{13}$ In our model goods price elasticities do not depend on the number of firms and varieties. One may consider an extension of the model establishing such a link. However, while improving the realism of our specification, we do not expect such an extension to overturn our main results. For instance, to the extent that a productivity gain that leads to exit also reduces the price elasticity of existing firms, terms of trade movements are likely to be attenuated in equilibrium, but not overturned.
} 
country-specific effects are given by:

$$
\begin{aligned}
& \frac{1}{n} \frac{d n_{t}}{d L_{t}}=\frac{1}{2[\psi+\gamma(1-\psi)]}+\frac{(\sigma-1)}{2(\sigma-\psi)}\left[1+\frac{2 \sigma \phi(1-\psi)}{\Delta}\right]>0 \\
& \frac{1}{n} \frac{d n_{t}^{*}}{d L_{t}}=\frac{1}{2[\psi+\gamma(1-\psi)]}-\frac{(\sigma-1)}{2(\sigma-\psi)}\left[1+\frac{2 \sigma \phi(1-\psi)}{\Delta}\right]
\end{aligned}
$$

The first expression above is always positive: the Home country always experiences an increase in the number of varieties produced locally. According to the 'Home market effect', as long as trade costs are positive and $\phi<1,{ }^{14}$ an increase in Home demand raises firms' incentive to enter into the Home market. The lower the trade costs, the easier is to invest in the high-demand country and still export to the other market: the advantage related to market size is then amplified by small trade costs (higher $\phi$ ). It follows that market size effects are stronger in economies that are more closely integrated.

In the Foreign country, the effect of a larger Home market is ambiguous, crucially depending on trade costs. When trade costs are low enough, competition by a larger number of Home firms is so strong that Foreign firms exit the market. Observe that when the utility from consumption is logarithmic $(\psi=1)$, a larger Home market size $L_{t}$ raises $n_{t}$ one to one, but leaves $n_{t}^{*}$ unaffected: from the viewpoint of Foreign producers the positive implications of a larger Home market are exactly offset by the increasing competition by a larger number of Home firms.

In our model, goods prices in domestic currency respond only to changes in productivity and wage rates, but not to changes in market size. We can therefore analyze terms of trade directions by looking exclusively at movements in the nominal exchange rate:

$$
\frac{d \varepsilon_{t}}{d L_{t}}=\frac{-(1-\phi)}{[2 \sigma-\psi(1-\phi)](1+\phi)}\left[1-\frac{\sigma(1-\phi)(1-\psi)}{\Delta}\right]<0
$$

A large Home market appreciates the Home currency, and therefore improves the Home terms of trade $p_{t} /\left(p_{t}^{*} \varepsilon_{t}\right)$. As regards factor prices, it raises Home wages and labor costs relative to their Foreign counterparts. Note that this effect vanishes when trade costs approach zero ( $\phi$ goes to 1$)$. In this case terms of trade and relative factor prices are constant since the increase in imports due to a larger market is exactly compensated by the increase in Home exports following the creation of new varieties.

A higher market size lowers the welfare-based Home CPI:

$$
\frac{1}{P} \frac{d P_{t}}{d L_{t}}=\frac{1}{1-\psi}\left(\frac{1}{n} \frac{d n_{t}}{d L_{t}}-1\right)<0
$$

This result reflects lower import prices (because of the exchange rate appreciation) as well as the larger set of goods available to consumers. As regards the Foreign price index, the

\footnotetext{
${ }^{14}$ In the case in which $\phi$ is exactly equal to 1 no Home market effect arises and the location of production of varieties is indeterminate.
} 
impact is ambiguous:

$$
\frac{1}{P} \frac{d P_{t}^{*}}{d L_{t}}=\frac{1}{1-\psi} \frac{1}{n} \frac{d n_{t}^{*}}{d L_{t}}
$$

The sign of the above expression is negative when trade costs are low enough and/or consumers have a strong taste for variety. In this case, the increase in the global number of varieties more than compensates the deterioration of the Foreign country's terms of trade.

Using the above welfare-based price indices, it is easy to show that a larger market size unambiguously depreciates the Home currency in real terms:

$$
\frac{1}{R E R} \frac{d R E R_{t}}{d L_{t}}=\frac{(1-\phi)}{(\sigma-\psi)(1-\phi)+(\sigma-1)(1+\phi)}\left(1-\psi \frac{d \varepsilon_{t}}{d L_{t}}\right)>0
$$

Note that the international price of consumption moves in the opposite direction relative to the international price of products: a weaker real exchange rate corresponds to stronger terms of trade. Conversely, using the 'empirically relevant' price indices $\widetilde{P}_{t}$ and $\widetilde{P}_{t}^{*}$ to compute the real exchange rate $\widetilde{R E R}_{t}$, we would have a real appreciation:

$$
\frac{1}{\widetilde{R E R}} \frac{d \widetilde{R E R_{t}}}{d L_{t}}=\frac{1-\phi}{1+\phi} \frac{d \varepsilon_{t}}{d L_{t}}<0
$$

If the real exchange rate is not correctly measured, changes in market size move the real exchange rate and the terms of trade in the same direction.

\subsection{Government spending}

Do countries with higher government spending have a stronger real exchange rate? Does government spending strengthen the competitive position of domestic producers by creating a larger market for their products? In this section we use our general-equilibrium model to address these issues. Note that asymmetries in public spending are qualitatively different from the asymmetries in country size discussed above in two important respects. First, differences in $L$ affect both goods demand and the labor force - the latter effect is obviously absent in an analysis of government spending $G$. Second, we assume that public consumption

falls entirely on domestically produced goods, while the (endogenous) home bias in private consumption expenditure associated with an increase in $L$ is much less pronounced.

We start our analysis by considering the effect of variations in Home government spending on the number of varieties:

$$
\begin{aligned}
& \frac{1}{n} \frac{d n_{t}}{d G_{t}}=\frac{1+2 \phi \psi(1-\psi)}{2(\sigma-\psi)}+\frac{1}{2(\sigma-1)[\psi+\gamma(1-\psi)]}>0 \\
& \frac{1}{n} \frac{d n_{t}^{*}}{d G_{t}}=-\frac{1+2 \phi \psi(1-\psi)}{2(\sigma-\psi)}+\frac{1}{2(\sigma-1)[\psi+\gamma(1-\psi)]}
\end{aligned}
$$

Under standard assumptions on elasticities, a larger government spending is associated with a higher number of firms in the Home country. The number of firms in the Foreign country 
can fall or increase, depending on trade costs and the parameter $\gamma$. As discussed above, when trade costs are low enough (higher $\phi$ ), it is easy to locate production in the high-demand country and still export to the other market.

As wages and prices do not respond to variations in government spending, the implications for relative labor costs $\left(w_{t} /\left(w_{t}^{*} \varepsilon_{t}\right)\right.$ and the terms of trade $p_{t} /\left(p_{t}^{*} \varepsilon_{t}\right)$ are once again captured by the response of the nominal exchange rate:

$$
\frac{d \varepsilon_{t}}{d G_{t}}=\frac{-\left[(\sigma-\psi)(\sigma-1)^{-1}(1-\phi)+1+\phi\right]}{[2 \sigma-\psi(1-\phi)](\sigma-1)+\sigma(1-\phi)(1-\psi)}<0
$$

The exchange rate appreciates, and therefore the terms of trade strengthen, due to the change in the number of varieties produced in the two countries. Stronger terms of trade, coupled with higher Home employment, imply that GDP in the Home country rises relative to the Foreign country.

The impact of higher government spending on the welfare-based CPI is ambiguous both at Home and in the Foreign country:

$$
\begin{gathered}
\frac{1}{P} \frac{d P_{t}}{d G_{t}}=\frac{1}{1-\psi}\left(\frac{1}{n} \frac{d n_{t}}{d G_{t}}-\frac{1}{\sigma-1}\right) \\
\frac{1}{P} \frac{d P_{t}^{*}}{d G_{t}}=\frac{1}{1-\psi} \frac{1}{n} \frac{d n_{t}^{*}}{d G_{t}}
\end{gathered}
$$

As a result, while the terms of trade are unambiguously stronger, the welfare-based real exchange rate may move in either direction:

$$
\frac{1}{R E R} \frac{d R E R_{t}}{d G_{t}}=\frac{-\psi(1-\phi)}{(\sigma-\psi)(1-\phi)+(\sigma-1)(1+\phi)} \frac{d \varepsilon_{t}}{d G_{t}}
$$

Yet, for plausible parameters' values, $R E R_{t}$ tends to be weaker in countries with larger government spending. Even though the terms of trade appreciate with higher public demand, the Home price index may fall relative to the Foreign index because of lower import prices, as well as the impact of changes in the number of varieties.

As discussed above, real exchange rate movements are quite different if the CPIs are computed using a consumption basket with a fixed number of varieties. Setting $d n_{t} / d G_{t}=$ $d n_{t}^{*} / d G_{t}=0$ in the above expressions, we obtain

$$
\frac{1}{\widetilde{R E R}} \frac{d \widetilde{R E R_{t}}}{d G_{t}}=\frac{1-\phi}{1+\phi} \frac{d \varepsilon_{t}}{d G_{t}}
$$

Note that an incorrectly measured real exchange rate would move in the same direction as the terms of trade and would unambiguously appreciate.

In conclusion, countries with higher (home-biased) government spending attract more varieties and have stronger terms of trade. However, consumers tend to face a lower price of 
consumption: government spending weakens the (correctly measured) real exchange rate although the 'empirically relevant' real exchange rate would suggest a different conclusion. Employment is higher, but domestic households have higher real private consumption. The spillover on Foreign consumption is negative: higher domestic $G$ reduces private consumption spending abroad.

Our model thus predicts a positive association of public consumption with both private consumption and GDP - a result that is reminiscent of Mundell-Fleming, but occurs for reasons that are entirely different from the Keynesian tradition. Our model does not predict that government spending strengthens real exchange rates - as sometimes implied by models that do not distinguish between terms of trade and the relative price of consumption. Rather, our analysis suggests that higher domestic demand improves the terms of trade but is likely to depreciate the real exchange rate, when the latter is correctly computed. The mechanism underlying the appreciation of the terms of trade is more sophisticated than a simple aggregate demand effect on domestically produced goods. Specifically, the 'home market effect' highlights possible competitive advantages for domestic producers stemming from a stronger domestic demand. However, future work should extend the analysis to the case of distortionary taxation, as to explore the trade-offs between market size and possible negative effects of a higher tax burden on investment and production.

\section{Welfare and international spillovers}

In this section we analyze the welfare dimension of international transmission. Specifically, we are interested in the sign of international spillovers from productivity gains and changes in market size and government spending. We will explore this issue by complementing our analytical results with numerical examples.

Depending on the interaction between love for varieties (parameterized by $\gamma$ ) and market power in production (parameterized by $\sigma$ ), the steady state number of varieties may be too low or too high relative to the planner's optimum (see Benassy (1996)). Taking the ratio of the planner's optimal number of varieties $n_{P}$ to the number of varieties supplied in a market allocation we obtain:

$$
\frac{n_{P}}{n}=\left[(\gamma-1) \sigma^{\psi}(\sigma-1)^{1-\psi}\right]^{\frac{1}{\psi+\gamma(1-\psi)}}
$$

Observe that with $\gamma=1$, i.e., no love for variety, the planner chooses a zero mass of varieties. In the standard Dixit-Stiglitz case with $\gamma=\sigma /(\sigma-1)$, the number of varieties in a market equilibrium is inefficiently low.

One of the advantages of our stylized model is that the indirect utility can be written 
as: ${ }^{15}$

$$
U_{t}=\frac{P^{1-\psi}}{1-1 / \psi}-\kappa \frac{\sigma n_{t}}{L_{t} \nu_{t}}=\frac{-P^{1-\psi}}{1-\psi}-p_{t} G_{t} \frac{n_{t}}{L_{t}}
$$

which makes the analysis of welfare changes extremely tractable, as effects of exogenous variations in fundamentals are completely determined by net entry/exit.

Consider first the welfare implications of trade liberalization and economic integration. In a model where the number of varieties is endogenous, a fall in trade costs $\tau$ has two effects (captured by the two terms in square brackets in the expression below): a direct effect on prices, which is obviously positive, and an indirect effect via the fall in goods variety. For variety-loving agents $(\gamma>1)$, the latter effect is clearly negative:

$$
\frac{d U_{t}}{d(1+\tau)}=-P^{1-\psi} \frac{(1+\tau)^{-\sigma}}{1+\phi}\left[1-\frac{(\gamma-1)(1-\psi)}{\gamma+\psi-\psi \gamma}\right]<0
$$

Echoing skeptical criticisms of globalization, one may wonder whether the disappearance of goods variety with trade integration may result into a loss of world welfare. This is not the case. As the expression above shows, the net effect of trade integration is always positive, and the direct effect via prices dominates the indirect one for any value of $\gamma$.

The welfare implications of changes in productivity and demand fundamentals can be summarized as follows:

$$
\begin{array}{rlrl}
\frac{d U_{t}}{d \alpha_{t}}=\frac{-P^{1-\psi}}{1-\psi} \frac{1}{n} \frac{d n_{t}}{d \alpha_{t}}>0 ; & & \frac{d U_{t}^{*}}{d \alpha_{t}}=\frac{-P^{1-\psi}}{1-\psi} \frac{1}{n} \frac{d n_{t}^{*}}{d \alpha_{t}} \\
\frac{d U_{t}}{d \nu_{t}}=\frac{-P^{1-\psi}}{1-\psi}\left(\frac{1}{n} \frac{d n_{t}}{d \nu_{t}}-1\right)>0 ; & \frac{d U_{t}^{*}}{d \nu_{t}}=\frac{-P^{1-\psi}}{1-\psi} \frac{1}{n} \frac{d n_{t}^{*}}{d \nu_{t}} \\
\frac{d U_{t}}{d L_{t}}=\frac{-P^{1-\psi}}{1-\psi}\left(\frac{1}{n} \frac{d n_{t}}{d L_{t}}-1\right)>0 ; & \frac{d U_{t}^{*}}{d L_{t}}=\frac{-P^{1-\psi}}{1-\psi} \frac{1}{n} \frac{d n_{t}^{*}}{d L_{t}} \\
\frac{d U_{t}}{d G_{t}}=\frac{-P^{1-\psi}}{1-\psi}\left(\frac{1}{n} \frac{d n_{t}}{d G_{t}}-\frac{\psi}{\sigma-1}\right) ; & \frac{d U_{t}^{*}}{d G_{t}}=\frac{-P^{1-\psi}}{1-\psi} \frac{1}{n} \frac{d n_{t}^{*}}{d G_{t}}
\end{array}
$$

The Home country always gains from higher domestic productivity and a larger market size. A rise in home-biased government expenditure has instead an ambiguous impact: even when such expenditure has no utility value, its net effect may be positive depending on the love for variety parameter. When this is high enough, relatively closed economies may experience welfare improvements because of the indirect effect of government spending on the supply of domestic goods variety. However, the numerical analysis below suggests that this case is unlikely.

The spillovers on the Foreign economy have all ambiguous sign. In general, trade integration (a higher $\phi$ ) make the Foreign welfare multipliers with respect to Home supply and demand innovations more positive (or less negative). Net welfare effects are also heavily

\footnotetext{
${ }^{15}$ Recall that $\pi_{t}=\kappa / \nu_{t}=L_{t} P_{t}^{1-\psi} /(\sigma n)+p_{t} G_{t} / \sigma$
} 
influenced by the parameter summarizing love for variety $\gamma$. For instance, in the presence of Home productivity gains in manufacturing, the global loss of variety can overturn Foreign welfare gains from lower import prices: if households value variety enough, the welfare multiplier turns from positive to negative. The same considerations apply to spillovers from Home efficiency gains reducing entry costs. Since the global number of varieties rises in this case, spillovers may be positive for Foreign agents — despite higher import prices — if they strongly value diversity.

To analyze welfare and the sign of international transmission, we carry out numerical exercises for three representative configurations of parameters. ${ }^{16}$ We take the standard Dixit-Stiglitz case as our benchmark case. Relative to this benchmark, we analyze a case in which the marginal taste for additional variety is lower - making it so low that the number of varieties in the market equilibrium is too high - and a case in which the marginal taste is higher - so that $n$ is too low.

In our numerical examples, we adopt that following parameters' values. In the baseline case, the elasticity of substitution between goods $\sigma$ is set equal to 5 . We also experiment with 2 and 10, values that are suggested by macro and trade studies, respectively. The intertemporal elasticity $\psi$ is set equal to 0.5 , but we also experiment with 0.2 and 1 . Trade costs $\tau$ are set as high as 50\% - this is to be interpreted as including both transport costs and the costs of policy-induced trade barriers, but not retail and wholesale margins. We experiment with a low value of $20 \%$ and a high value of $70 \%$. The latter value reflects evidence reported in the survey by Anderson and van Wincoop (2004), who estimate trade costs for the U.S. as high as $74 \% .{ }^{17}$ Without loss of generality, we normalize marginal disutility of labor units such that $\kappa=1$.

Table 1 shows our results for $\gamma=\sigma /(\sigma-1)$. The table reports welfare results for all cases, but to save space the effect on the number of varieties is shown for the baseline case only. Our results are as follows.

In the baseline case, gains in Home manufacturing productivity raise welfare at Home and abroad: private consumption increases, while labor effort decreases, in both countries. At Home, gains in consumption are due to a fall in the price of both domestically produced goods and imports - the latter because of exchange rate appreciation. Abroad, the fall in the CPI is entirely due to cheaper imports, as a result of a weaker currency, and a lower

\footnotetext{
${ }^{16}$ In the Tables, net welfare gains $d U$ and $d U^{*}$ are reported in terms of percentage consumption equivalents. For instance, denoting $u$ the net welfare gain in the Home country, $C_{0}$ and $\ell_{0}$ the before-shock levels of Home consumption and labor effort, and $\ell_{1}$ the after-shock level of labor effort, $u$ solves $U\left[C_{0}(1+u / 100), \ell_{0}\right]=$ $U\left[C_{1}, \ell_{1}\right]$.

17 The breakdown is $21 \%$ transportation costs and $44 \%$ border-related trade barriers $(1.74=1.21 * 1.44)$.
} 
Table 1: The Dixit-Stiglitz case with love for variety tied to the elasticity of substitution: $\gamma=\frac{\sigma}{\sigma-1}$

\begin{tabular}{|l|cc|cc|cc|cc||}
\hline & \multicolumn{2}{|c|}{$\alpha$} & \multicolumn{2}{|c|}{$\nu$} & \multicolumn{2}{|c|}{$G$} & \multicolumn{2}{|c||}{$L$} \\
\cline { 2 - 9 } & & & & & & & & \\
$\sigma=5 ; \psi=0.5$ & & & & & & & & \\
$\tau=0.5 ; \gamma=1.25$ & & & & & & & & \\
& $d n / n$ & $d n^{*} / n$ & $d n / n$ & $d n^{*} / n$ & $d n / n$ & $d n^{*} / n$ & $d n / n$ & $d n^{*} / n$ \\
Cons. equivalent & -.437 & -.004 & .890 & -.001 & .223 & .000 & .899 & -.011 \\
& $d U$ & $d U^{*}$ & $d U$ & $d U^{*}$ & $d U$ & $d U^{*}$ & $d U$ & $d U^{*}$ \\
& .882 & .007 & .219 & .002 & -.197 & -.001 & .200 & .021 \\
Sensitivity analysis & & & & & & & & \\
Cons. equivalent & $d U$ & $d U^{*}$ & $d U$ & $d U^{*}$ & $d U$ & $d U^{*}$ & $d U$ & $d U^{*}$ \\
$\sigma=3$ & .773 & .026 & .385 & .014 & -.311 & .006 & .312 & .087 \\
$\sigma=10$ & .949 & .001 & .104 & -.001 & -.101 & -.001 & .103 & .001 \\
$\psi=0.2$ & .841 & .003 & .207 & -.000 & -.198 & .000 & .188 & .018 \\
$\psi=1$ & .978 & .017 & .244 & .005 & -.191 & .001 & .222 & .027 \\
$\tau=0.2$ & .869 & .021 & .216 & .005 & -.198 & .000 & .168 & .053 \\
$\tau=0.7$ & .886 & .007 & .220 & .001 & -.197 & -.001 & .208 & .013 \\
\hline
\end{tabular}

supply price of Home goods. In either country, the fall in prices more than compensates in welfare terms the contraction in the number of varieties available to consumers.

International spillovers are stronger when goods market are more integrated. Lowering trade costs (from $\tau=0.7$ to $\tau=0.2$ ) raises the welfare gains in the Foreign country, while reducing the welfare gains in the Home country. Conversely, the Home country welfare rises with a higher elasticity $\sigma$ and a higher elasticity $\psi$. The implications of gains in efficiency reducing entry costs are quite similar: welfare tends to improve everywhere, per effect of higher consumption and lower labor effort. The benefits for the Foreign country are however contained, relative to the previous case, and can be actually slightly negative when the elasticity $\sigma$ is high.

Both countries benefit from a larger Home market size, simultaneously increasing expenditure and labor supply: consumption rises and individual labor effort falls everywhere in the world economy. Yet welfare improvements are stronger in the Home country than abroad. Trade liberalization magnifies international spillovers: the benefits of a larger Home market accruing to Foreign agents increase (while the benefits for Home agents fall) when trade costs are lowered from 70 to 20 percent.

Disregarding utility from public goods, higher Home government spending clearly reduces Home welfare (it is beggar-thyself): even though higher spending raises the number of varieties produced in the country and raises private consumption, the extra effort required 
Table 2: The case with low love for variety; $\gamma=1.15$

\begin{tabular}{||l|cc|cc|cc|cc||}
\hline \multirow{3}{*}{ Base case } & \multicolumn{2}{|c|}{$\alpha$} & \multicolumn{2}{|c|}{$\nu$} & \multicolumn{2}{|c|}{$G$} & \multicolumn{2}{|c||}{$L$} \\
\cline { 2 - 10 } & \multicolumn{1}{|c|}{$d n / n$} & $d n^{*} / n$ & $d n / n$ & $d n^{*} / n$ & $d n / n$ & $d n^{*} / n$ & $d n / n$ & $d n^{*} / n$ \\
Cons. equivalent & -.447 & -.015 & .910 & .020 & .228 & .005 & .920 & .010 \\
& $d U$ & $d U^{*}$ & $d U$ & $d U^{*}$ & $d U$ & $d U^{*}$ & $d U$ & $d U^{*}$ \\
& .902 & .029 & .178 & -.040 & -.207 & -.011 & .158 & -.020 \\
Sensitivity analysis & & & & & & & & \\
Cons. equivalent & $d U$ & $d U^{*}$ & $d U$ & $d U^{*}$ & $d U$ & $d U^{*}$ & $d U$ & $d U^{*}$ \\
$\tau=0.2$ & .890 & .042 & .174 & -.037 & -.208 & -.010 & .127 & .011 \\
$\tau=0.7$ & .906 & .026 & .178 & -.041 & -.207 & -.011 & .167 & -.029 \\
\hline
\end{tabular}

to satisfy total demand dominates the welfare results. International spillovers tend to be small: changes in Foreign welfare due to Home government consumption tend to be very close to zero. Both Foreign consumption and labor effort fall. Note that the gains tend to be positive when we lower the elasticity of substitution $(\sigma=3)$, relative to our base case.

We now turn to the case where love for variety can be distinguished from the elasticity of substitution. We start with the case with low love for variety $\gamma=1.15$. We report our results in Table 2, which, for the sake of space, only show changes in the number of varieties and welfare.

A notable difference relative to Table 1 , is that international spillovers in all cases but improvements in manufacturing productivity tend to become negative. The reason is that Foreign agents do not particularly value the increase in the number of goods varieties due to Home gains in productivity reducing entry costs, Home government spending and/or market size. Foreign agents are thus worse off because of higher import prices. Conversely, Foreign agents benefits from lower goods prices associated with higher manufacturing productivity, as the contraction in goods varieties associated with it has small welfare consequences. Note however that when trading costs are sufficiently low, an increase in Home market size benefits foreign residents.

The opposite picture emerges in Table 3, where we experiment with a relatively high love for variety. In this case, gains in Home productivity in manufacturing is detrimental to Foreign agents, because of the negative effect on variety. For the same reason, spillovers are positive in all other cases. 
Table 3: The case with high love for variety; $\gamma=1.75$

\begin{tabular}{|c|c|c|c|c|c|c|c|c|}
\hline \multirow{2}{*}{ Base case } & \multicolumn{2}{|c|}{$\alpha$} & \multicolumn{2}{|c|}{$\nu$} & \multicolumn{2}{|c|}{$G$} & \multicolumn{2}{|c|}{$L$} \\
\hline & $d n / n$ & $d n^{*} / n$ & $d n / n$ & $d n^{*} / n$ & $d n / n$ & $d n^{*} / n$ & $d n / n$ & $d n^{*} / n$ \\
\hline \multirow{3}{*}{ Cons. equivalent } & -.397 & .036 & .808 & -.082 & .203 & -.021 & .818 & -.091 \\
\hline & $d U$ & $d U^{*}$ & $d U$ & $d U^{*}$ & $d U$ & $d U^{*}$ & $d U$ & $d U^{*}$ \\
\hline & .800 & -.071 & .381 & .164 & -.156 & .040 & .362 & .183 \\
\hline Sensitivity analysis & & & & & & & & \\
\hline Cons. equivalent & $d U$ & $d U^{*}$ & $d U$ & $d U^{*}$ & $d U$ & $d U^{*}$ & $d U$ & $d U^{*}$ \\
\hline$\tau=0.2$ & .787 & -.059 & .378 & .167 & -.157 & .041 & .330 & .215 \\
\hline$\tau=0.7$ & .804 & -.075 & .382 & .163 & -.156 & .040 & .370 & .175 \\
\hline
\end{tabular}

\section{Conclusion}

Understanding the determinants of international relative prices of a country's output and consumption is a crucial challenge to international macroeconomics and policy making. National wealth depends not only on the quantity of goods and services that a country can produce now and in the future, but also on the relative prices of such goods and services in the international markets. Productivity innovations that raise a country output may raise national welfare abroad, to the extent that they drive down import prices. However, when innovations also change the attributes of consumption goods, leading to product diversification, a correct assessment of the value of output, consumption and imports to consumers requires an assessment of consumers' preferences for goods variety. In this paper we have provided a stylized framework to address these issues.

Our results stress the importance of a reconsideration of the deep parameters underlying macro policy models. Not only the effects of productivity improvements on the equilibrium allocation depends on the nature of productivity gain (whether it is in manufacturing or affecting the cost of firms' entry and innovation). The sign of international spillovers also depends on the relative strength of different effects of productivity - strengthening monopoly power vs. raising utility by making additional goods varieties available to consumers.

An important direction for future research indeed consists of enriching the model specification by modelling the introduction of new varieties and firms' entry as investment activities - allowing for time to build, while at the same time accounting for financial or nominal price rigidities that would motivate stabilization policies. 


\section{References}

[1] Anderson, J. and E. van Wincoop, 2003, "Trade Costs." Journal of Economic Literature, 42 (3), pp. 691-751.

[2] Acemoglu, D. and J. Ventura, 2002, "The World Income Distribution." Quarterly Journal of Economics, 117 (2), pp. 659-94.

[3] Baldwin R. and R. Forslid, 2004, "Trade Liberalization with Heterogenous Firms." CEPR Discussion Paper No. 4635.

[4] Benassy, J-P., 1996, "Taste for Variety and Optimum Production Patterns in Monopolistic Competition." Economics Letters 52, pp. 41-47.

[5] Bergin P. and R. Glick, 2003, "Endogenous Nontradability and Macroeconomic Implications." NBER Working Paper No. 9739.

[6] Broda, C. and D. Weinstein, 2004a, "Globalization and the Gains from Variety." NBER Working Paper No. 10314

[7] Broda, C. D. Weinstein, 2004b, "Variety Growth and World Welfare." American Economic Review Papers and Proceedings 94 (2), pp. 139-144.

[8] Debaere, P. and H. Lee, 2004, "The Real-Side Determinants of Countries Terms of Trade: a Panel Data Analysis." University of Texas at Austin, Mimeo.

[9] Dixit, A.K. and J. Stiglitz, 1974, "Monopolistic Competition and Optimum Product Diversity," original working paper version published in Brakman and Heijdra (eds.), The monopolistic competition revolution in retrospect, 2003, Cambridge University Press.

[10] Dixit, A.K. and J.E. Stiglitz, 1977, "Monopolistic Competition and Optimum Product Diversity." American Economic Review, 67 (3), pp. 297-308.

[11] Feenstra, R., 1994, "New Product Varieties and the Measurement of International Prices," American Economic Review 84(1), pp. 157-177.

[12] Ghironi, F. and M. Melitz, 2004, "International Trade and Macroeconomics Dynamics with Heterogenous Firms." NBER Working Paper No. 10540.

[13] Krugman, P. , 1980, "Scale Economies, Product Differentiation, and the Pattern of Trade." American Economic Review 70, pp. 950-959. 
[14] Krugman, P., 1989, "Differences in Income Elasticities and Trends in Real Exchange Rates." European Economic Review 33, pp. 1031-1054.

[15] Melitz M., 2003, "The Impact of Intra-industry Reallocations and Aggregate Industry Productivity." Econometrica 71, pp. 1695-1725. 